\title{
Reaction Mechanism and Process Control of Hydrogen Reduction of Ammonium Perrhenate
}

\author{
Junjie Tang ${ }^{1,2}$, Yuan Sun ${ }^{2, *}$, Chunwei Zhang ${ }^{2,3}$, Long Wang ${ }^{2}$, Yizhou Zhou ${ }^{2, *}$, Dawei Fang ${ }^{3}$ \\ and Yan Liu 4 \\ 1 School of Biomedical \& Chemical Engineering, Liaoning Institute of Science and Technology, \\ Benxi 117004, China; tangjunjieyh@lnist.edu.cn \\ 2 Superalloys research department, Institute of Metal Research, Chinese Academy of Sciences, \\ Shenyang 110016, China; 13842034917@163.com (C.Z.); wanglong@imr.ac.cn (L.W.) \\ 3 College of chemistry, Liaoning University, Shenyang 110036, China; davidfine@163.com \\ 4 Key Laboratory for Ecological Utilization of Multimetallic Mineral, Ministry of Education, \\ Northeastern University, Shenyang 110819, China; liuyan@smm.neu.edu.cn \\ * Correspondence: yuansun@imr.ac.cn (Y.S.); yzzhou@imr.ac.cn (Y.Z.); \\ Tel.: +86-024-23971767 (Y.S.); +86-024-83978068 (Y.Z.)
}

Received: 17 April 2020; Accepted: 13 May 2020; Published: 15 May 2020 updates

\begin{abstract}
The preparation of rhenium powder by a hydrogen reduction of ammonium perrhenate is the only industrial production method. However, due to the uneven particle size distribution and large particle size of rhenium powder, it is difficult to prepare high-density rhenium ingot. Moreover, the existing process requires a secondary high-temperature reduction and the deoxidization process is complex and requires a high-temperature resistance of the equipment. Attempting to tackle the difficulties, this paper described a novel process to improve the particle size distribution uniformity and reduce the particle size of rhenium powder, aiming to produce a high-density rhenium ingot, and ammonium perrhenate is completely reduced by hydrogen at a low temperature. When the particle size of the rhenium powder was $19.74 \mu \mathrm{m}$, the density of the pressed rhenium ingot was $20.106 \mathrm{~g} / \mathrm{cm}^{3}$, which was close to the theoretical density of rhenium. In addition, the hydrogen reduction mechanism of ammonium perrhenate was investigated in this paper. The results showed that the disproportionation of $\mathrm{ReO}_{3}$ decreased the rate of the reduction reaction, and the XRD and XPS patterns showed that the increase in the reduction temperature was conducive to increasing the reduction reaction rate and reducing the influence of disproportionation on the reduction process. At the same reduction temperature, reducing the particle sizes of ammonium perrhenate was conducive to increasing the hydrogen reduction rate and reducing the influence of the disproportionation.
\end{abstract}

Keywords: ammonium perrhenate; rhenium; disproportionation reaction; hydrogen reduction

\section{Introduction}

Rhenium as an important rare metal is widely used in metallurgy and the aerospace industry [1]. The plasma method, electrolysis method, vapor deposition method, and powder metallurgy are the main processes for the preparation of rhenium [2,3]. Jurewicz et al. [4] prepared a high-purity nanometer rhenium powder by the plasma method. Leonhardt et al. [5] used plasma spray spheroidization to control the microstructure of rhenium and obtained spherical rhenium powders. Schrebler et al. [6] also prepared spherical rhenium powder from a mixture of rhenic acid and sodium sulfate by electrolysis. Liu et al. [7] prepared small particles of superfine spherical rhenium powder by vapor deposition. The rhenium powders prepared by the above processes have a uniform particle size distribution and large specific surface area, and the pure rhenium materials prepared from these rhenium powders 
have high densities. However, due to the complexity of the above processes and high equipment requirements, none of the above processes have been industrialized. The hydrogen reduction of ammonium perrhenate is a commonly used process to prepare rhenium powder in industry, which has the characteristics of a simple process flow, low production cost, and low equipment requirements [8,9]. The preparation process flow chart of rhenium ingot is shown in Figure 1. However, the rhenium powders that are produced by this preparation technology have an uneven particle size distribution, small specific surface area, and the rhenium ingots produced have poor compactness. Moreover, due to the low efficiency of the mass and heat transfer in the traditional process, the reaction with hydrogen is not complete and the second reduction step at a high temperature is required [10-12].

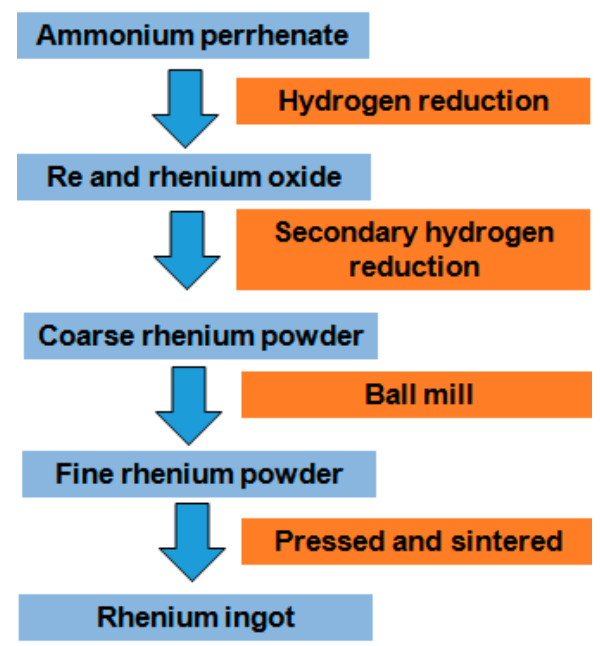

Figure 1. Industrial preparation of rhenium ingots.

In order to optimize the process of preparing rhenium by a high-temperature reduction, we can look into work dealing with the preparation of other metal powders by a high-temperature reduction. In recent years, there have been many studies on the preparation of metal powders by a high-temperature hydrogen reduction [13-21]. For instance, Wang et al. [22] proposed a novel route to synthesize Mo powders via a carbothermic prereduction of molybdenum oxide followed by a reduction by hydrogen; they removed oxygen from the samples by a secondary reduction. Kanga et al. [23] prepared nanosized $\mathrm{W}$ and $\mathrm{W}-\mathrm{Ni}$ powders by applying ball milling and a hydrogen reduction of oxide powders. Gua et al. [24] prepared Mo nanopowders through a hydrogen reduction of a combustion-synthesized foam-like $\mathrm{MoO}_{2}$ precursor. All of the above studies are based on a reducing substance pretreatment, which provides a certain reference experience for this study. However, the hydrogen reduction reaction of ammonium perrhenate is a complicated process. This process not only involves reduction, but also a disproportionation reaction. Colton [25] pointed out that the disproportionation of $\mathrm{ReO}_{3}$ occurred above $300{ }^{\circ} \mathrm{C}$ to produce $\mathrm{Re}_{2} \mathrm{O}_{7}$ and $\mathrm{ReO}_{2}$. This disproportionation reaction is the main reason why ammonium perrhenate cannot be completely reduced to rhenium at a low temperature. There are few reports on the preparation of a high-quality Re powder by a hydrogen reduction at present. Bai et al. [26] reduced volatile rhenium oxide to prepare Re powder. However, due to the high equipment requirements of this process, it cannot be used for industrial production.

\section{Chemical Reaction Considerations}

Ammonium perrhenate decomposes into oxides with different valence states when reduced at a high temperature, and the main oxides are $\mathrm{Re}_{2} \mathrm{O}_{7}, \mathrm{ReO}_{3}$, and $\mathrm{ReO}_{2}$ [27]. The total equation for the reduction of ammonium perrhenate in hydrogen is represented by Equation (1). Ammonium perrhenate is decomposed by heat to $\mathrm{Re}_{2} \mathrm{O}_{7}$, which is gradually recombined with hydrogen and finally 
reduced to $\mathrm{Re}$, as shown in Equations (2)-(4). $\mathrm{ReO}_{3}$ is very reactive; $\mathrm{ReO}_{3}$ is disproportionated at a high temperature to produce $\mathrm{ReO}_{2}$ and $\mathrm{Re}_{2} \mathrm{O}_{7}$, as shown in Equation (5).

$$
\begin{gathered}
2 \mathrm{NH}_{4} \operatorname{ReO}_{4}(\mathrm{~s})+7 \mathrm{H}_{2}(\mathrm{~g})=2 \operatorname{Re}(\mathrm{s})+8 \mathrm{H}_{2} \mathrm{O}(\mathrm{g})+2 \mathrm{NH}_{3}(\mathrm{~g}) \\
\operatorname{Re}_{2} \mathrm{O}_{7}(\mathrm{~s})+\mathrm{H}_{2}(\mathrm{~g})=2 \operatorname{ReO}_{3}(\mathrm{~s})+\mathrm{H}_{2} \mathrm{O}(\mathrm{g}) \\
\operatorname{ReO}_{3}(\mathrm{~s})+\mathrm{H}_{2}(\mathrm{~g})=\operatorname{ReO}_{2}(\mathrm{~s})+\mathrm{H}_{2} \mathrm{O}(\mathrm{g}) \\
\operatorname{ReO}_{2}(\mathrm{~s})+2 \mathrm{H}_{2}(\mathrm{~g})=\operatorname{Re}(\mathrm{s})+2 \mathrm{H}_{2} \mathrm{O}(\mathrm{g}) \\
3 \operatorname{ReO}_{3}(\mathrm{~s})=\operatorname{Re}_{2} \mathrm{O}_{7}(\mathrm{~s})+\operatorname{ReO}_{2}(\mathrm{~s})
\end{gathered}
$$

In the present work, we determined the reduction mechanism of ammonium perrhenate through a differential thermal analysis, and innovatively proposed that the disproportionation reaction in the reduction process was the main reason affecting the complete reduction of ammonium perrhenate. This work also determined an innovative process for reducing the particle size and reduction temperature of rhenium powder, aiming to produce a high-density rhenium ingot, and ammonium perrhenate is completely reduced by hydrogen at a low temperature. This is the technological innovation point of this paper. Moreover, the optimization and innovation of this process is based on the already industrialized hydrogen reduction process to produce rhenium ingot, which makes it easy to realize as an industrialized production process.

\section{Materials and Methods}

\subsection{Instrument}

Instrument: The following instruments were used herein: RE-2000A rotary evaporator, Qiqiang instrument manufacturing co. LTD, Shanghai, China; SSX-550 scanning electron microscope, Shimadzu, Osaka, Japan; PW3040/60 X-ray diffractometer (XRD), Panalytical Company, Almelo, Netherlands; Escalab250 250 X-ray photoelectron spectroscopy (XPS), Hewlett-Packard Company, Palo alto, CA, USA; VEP223 high-temperature vacuum sintering furnace, Beizhen Vacuum Technology Co. Ltd., Shenyang, China; HYL-1076 laser particle size analyzer, Haoyu Technology Co. Ltd., Dandong, China; the self-developed recrystallization reactor, Institute of metals, Chinese academy of sciences, Shenyang, China; STA PT1600 Differential Thermal Analysis (DTA), Linseis Co. Ltd., Selb, Germany.

\subsection{Materials}

Materials: $\mathrm{NH}_{4} \mathrm{ReO}_{4}(99.99 \%, \mathrm{Re} \geq 69.4 \%)$ from Halin Chemical Co. LTD, Weifang, China.

\subsection{Analytical Methods}

XRD detection: The light tube type was a Cu target, ceramic $X$ light tube. $\lambda=0.15406 \mathrm{~nm}$, scan range was 10-90 degrees, the scanning speed was 2 degrees $/ \mathrm{min}$.

DTA detection: The temperature ranged from 300 to $700{ }^{\circ} \mathrm{C}$, and the gas atmosphere was nitrogen.

Particle size distribution detection: the test medium was ethanol, the optical model was Mie, and the distribution type was volume distribution.

The parameters of SEM: The electron acceleration voltage was $20.0 \mathrm{KV}$, the working distance was $21.8 \mathrm{~mm}$, and the magnification was 15,000 times.

XPS analysis parameters: The fitting software was XPSPEAK (XPSPEAK.41, Hewlett-Packard Company, Palo alto, CA, USA). The read base pressure was $2.4 \times 10^{-8} \mathrm{~Pa}$, utilizing monochromatic Al $\mathrm{K} \alpha$ radiation operating at $1486.6 \mathrm{eV}$. At the pass energy of $50 \mathrm{eV}$, with a $0.1 \mathrm{eV}$ step, the high-resolution scans were performed. At the pass energy of $100 \mathrm{eV}$ and a step size of $1 \mathrm{eV}$, the survey spectra were acquired. The reproducible C (1 s) binding energy of all samples was $284.6 \mathrm{eV}$ and the charge 
neutralization was achieved using low-energy electrons and argon ions. The spin-orbit splitting was $2.4 \mathrm{eV}$, and the spin orbital split intensity ratio of $4 \mathrm{f}_{7 / 2}$ and $4 f_{5 / 2}$ was $4: 3$.

\subsection{Experimental Procedure}

As illustrated by Figure 2 was the experimental flow chart of a hydrogen reduction of ammonium perrhenate in this study. Ammonium perrhenate $(99.99 \%, \operatorname{Re} \geq 69.4 \%$ ) was prepared with deionized water into a saturated solution at room temperature, the room temperature was about $25{ }^{\circ} \mathrm{C}$. Then the saturated solution of ammonium perrhenate at room temperature was placed in an RE-2000A rotary evaporator, and part of the water was evaporated to form a hot saturated solution at $120{ }^{\circ} \mathrm{C}$ [28]. The thermally saturated solution of ammonium perrhenate was introduced into the recrystallization condensation reactor; the stirring speed and cooling temperature were adjusted and recrystallized at $5^{\circ} \mathrm{C}$ for $3 \mathrm{~h}$. Finally, the cooled solid-liquid mixture was filtered and dried to obtain ammonium perrhenate crystals. The SEM diagrams of the recrystallized ammonium perrhenate are shown in Figure 3 [29], and the median diameters $\left(\mathrm{D}_{50}\right)$ and specific surface area are shown in Table 1 . The recrystallization ammonium perrhenate particles $(60 \mathrm{~g})$ were reduced with the different temperatures $\left(300-900{ }^{\circ} \mathrm{C}\right)$ in the high-temperature vacuum sintering furnace; the hydrogen flow rate was $500 \mathrm{~mL} / \mathrm{min}$, and the heating rate was $10^{\circ} \mathrm{C} / \mathrm{min}$. After $3 \mathrm{~h}$ of reduction, the reduction product of ammonium perrhenate was obtained.

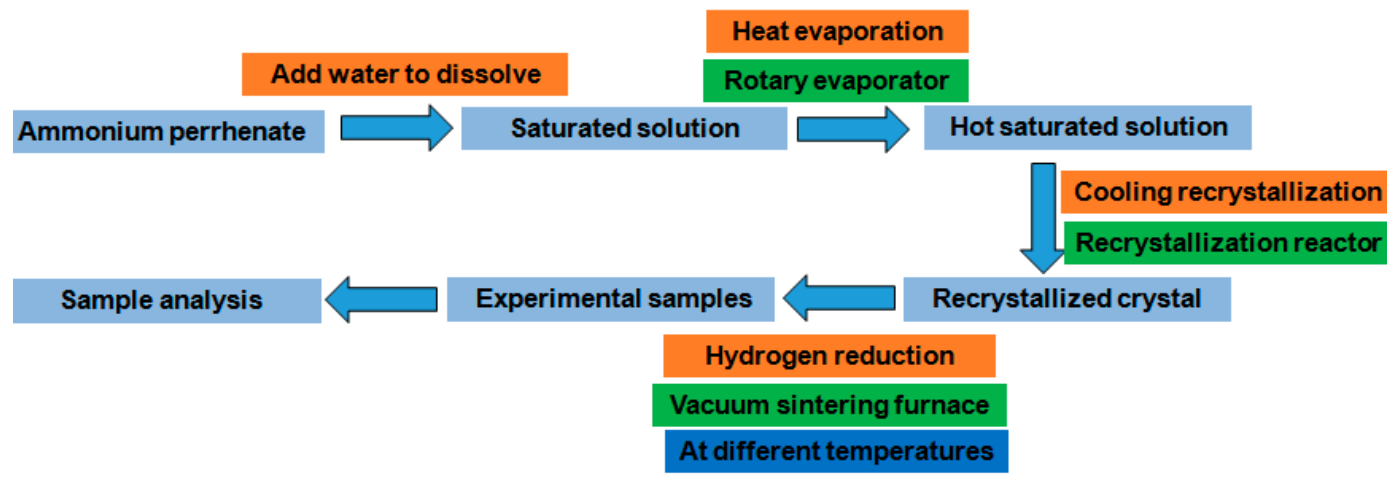

Figure 2. The experimental working procedure diagram.

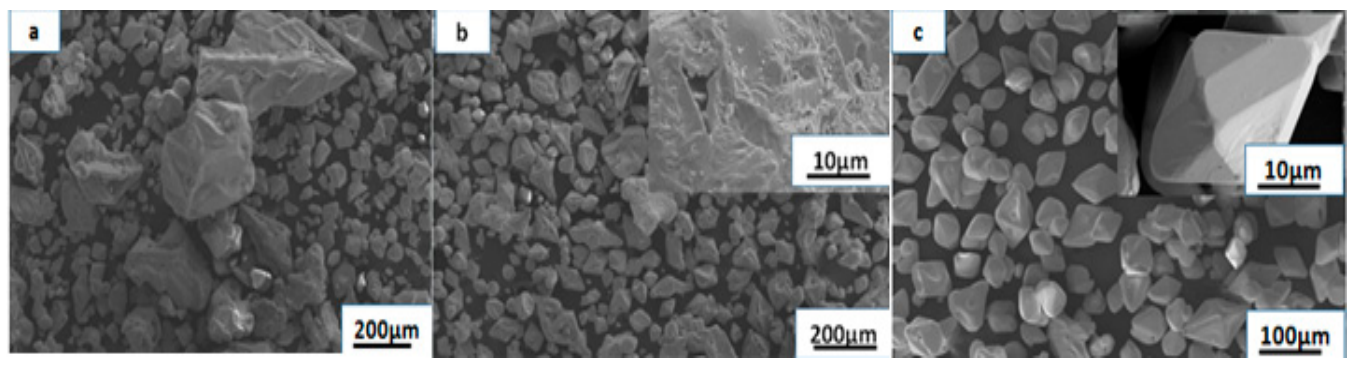

Figure 3. SEM images of recrystallized ammonium perrhenate particles at different agitation intensities and ammonium perrhenate raw material particles (a) ammonium perrhenate raw material particles, (b) $100 \mathrm{rpm}$ stirring strength recrystallized particles, and (c) $200 \mathrm{rpm}$ stirring strength recrystallized particles) [29].

Table 1. Specific surfaces and median diameters $\left(\mathrm{D}_{50} \mathrm{~s}\right)$ of the NH4ReO4 particles.

\begin{tabular}{ccc}
\hline Ammonium Perrhenate & Specific Surface $\left(\mathrm{m}^{2} / \mathbf{k g}\right)$ & $\mathrm{D}_{\mathbf{5 0}}(\mu \mathrm{m})$ \\
\hline $\begin{array}{c}100 \text { rpm stirring strength } \\
\text { recrystallized }\end{array}$ & 21.72 & 81.05 \\
$\begin{array}{c}\text { 200 rpm stirring strength } \\
\text { recrystallized }\end{array}$ & 26.93 & 71.17 \\
Raw material particles & 14.79 & 123.90 \\
\hline
\end{tabular}


Preparation of rhenium ingots: $20 \mathrm{~g}$ rhenium powder was put into the powder press mold (the height was $32.00 \mathrm{~mm}$ and the inner diameter of the mould was $16.60 \mathrm{~mm}$ ) to press. The pressure of the powder press was $74,000 \mathrm{~N}$, the sintering furnace temperature was $2300{ }^{\circ} \mathrm{C}$, and the sintering time was $3 \mathrm{~h}$. The theoretical density of rhenium is $21.04 \mathrm{~g} / \mathrm{cm}^{3}$.

\section{Results and Discussion}

\subsection{Reduction Mechanism Analysis}

In order to research the reaction mechanism of ammonium perrhenate in the reduction process, the decomposition products of ammonium perrhenate $\left(\mathrm{Re}, \mathrm{ReO}_{2}\right.$, and $\left.\mathrm{ReO}_{3}\right)$ were analyzed by a differential thermal analysis (DTA), and the differential thermal analysis curve is shown in Figure 4. It can be seen that an obvious endothermic peak appeared at 350 to $400{ }^{\circ} \mathrm{C}$. Re is stable at a high temperature, and the decomposition temperature of $\mathrm{ReO}_{2}$ is $700{ }^{\circ} \mathrm{C}$. Therefore, the generation of this endothermic peak can only be due to the disproportionation of $\mathrm{ReO}_{3}$. The disproportionation reaction products of $\mathrm{ReO}_{3}$ are $\mathrm{ReO}_{2}$ and $\mathrm{Re}_{2} \mathrm{O}_{7}$, and the reaction equation is shown in Equation (5). In the hydrogen reduction process, the ammonium perrhenate is firstly decomposed into $\operatorname{Re}_{2} \mathrm{O}_{7}, \operatorname{the}_{2} \operatorname{Re}_{2} \mathrm{O}_{7}$ reacts with hydrogen to form $\mathrm{ReO}_{3}$, and $\mathrm{ReO}_{3}$ reacts with hydrogen to form $\mathrm{ReO}_{2}$ until they are reduced to Re. In the process of a hydrogen reduction of ammonium perrhenate, if the disproportionation reaction and reduction reaction exist simultaneously, the disproportionation reaction will be the main reason affecting the complete reduction of ammonium perrhenate at a low temperature.

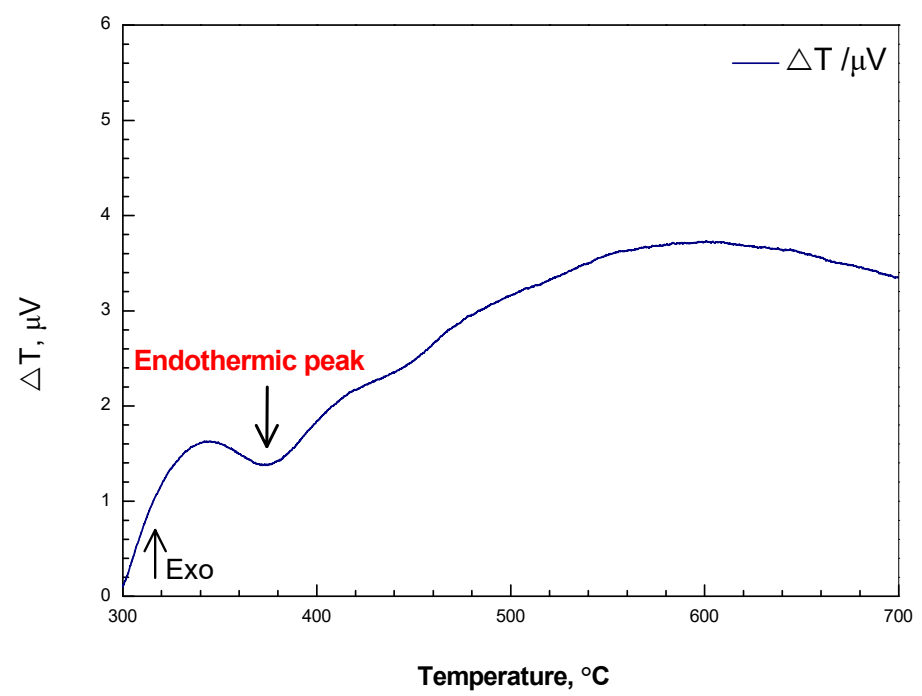

Figure 4. The differential thermal analysis curve of $\mathrm{Re}, \mathrm{ReO}_{2}$, and $\mathrm{ReO}_{3}$.

In order to research the effect of disproportionation on the hydrogen reduction of ammonium perrhenate, the hydrogen reduction experiments of ammonium perrhenate were carried out at the same reduction time and at different reduction temperatures. The reducing substance was recrystallized ammonium perrhenate at a $200 \mathrm{rpm}$ stirring strength $\left(\mathrm{D}_{50}\right.$ was $71.17 \mu \mathrm{m}$, specific surface was $26.93 \mathrm{~m}^{2} / \mathrm{kg}$ ). The XRD patterns of the reduction products of ammonium perrhenate at different temperatures are shown in Figure 5. The characteristic peaks of the reduction products were complex at lower temperatures $\left(300-600^{\circ} \mathrm{C}\right)$, and the diffraction peaks of the reduction products indicated Re and $\mathrm{ReO}_{2}$, and $\mathrm{ReO}_{3}$. The characteristic peaks of Re did not change obviously from 400 to $600{ }^{\circ} \mathrm{C}$. However, in the range of 300 to $400{ }^{\circ} \mathrm{C}$, the characteristic peaks of $\mathrm{ReO}_{3}$ were enhanced. In the range of 400 to $600{ }^{\circ} \mathrm{C}$, the characteristic peaks of $\mathrm{ReO}_{2}$ were enhanced, while that of $\mathrm{ReO}_{3}$ were weakened. When the temperature reached $700{ }^{\circ} \mathrm{C}$, the characteristic peaks of the reduction products were $\mathrm{Re}$, and other crystal peaks were not observed. This result suggested that the contents of $\mathrm{ReO}_{3}$ in the reduction products increased in the range of 300 to $400{ }^{\circ} \mathrm{C}$. However, within the temperature range of 400 to 
$600{ }^{\circ} \mathrm{C}$, the content of Re in the reduction products did not increase significantly, while the content of $\mathrm{ReO}_{2}$ increased significantly.
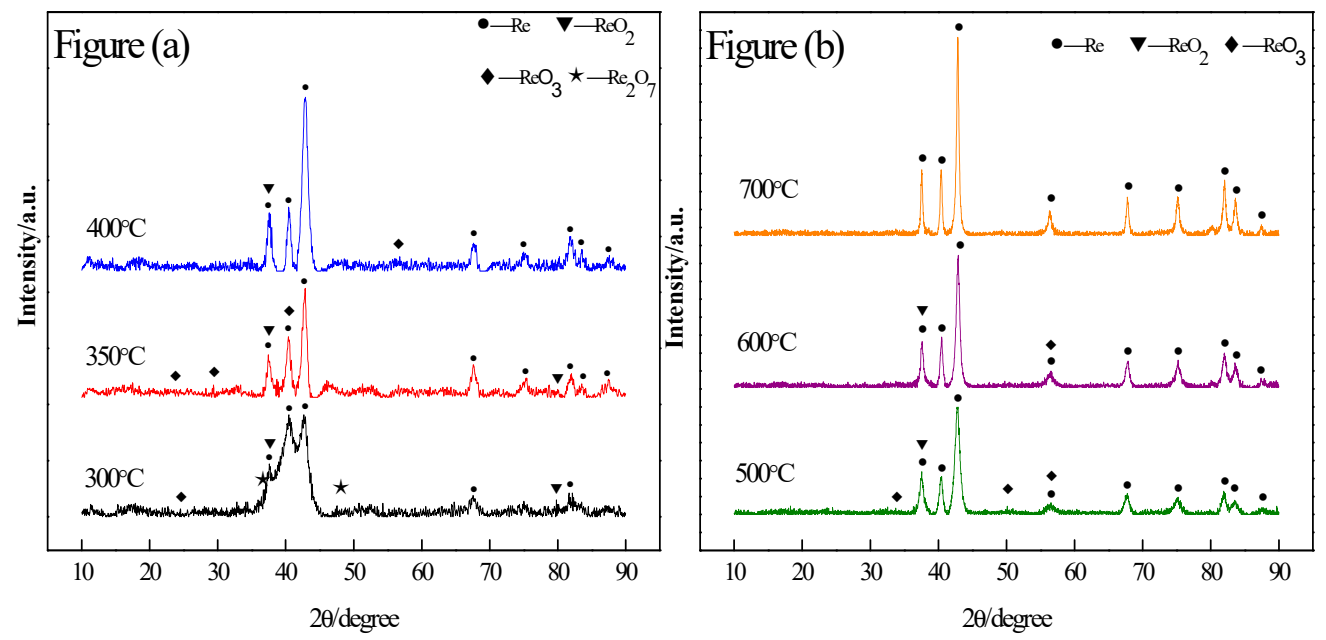

Figure 5. XRD patterns of the reduction products of ammonium perrhenate $\left(\mathrm{D}_{50}\right.$ was $71.17 \mu \mathrm{m}$, specific surface was $26.93 \mathrm{~m}^{2} / \mathrm{kg}$ ) at different temperatures. Figure (a) was the XRD diffraction pattern of the reduced product at 300 to $400{ }^{\circ} \mathrm{C}$; Figure (b) was the XRD diffraction pattern of the reduced product at 500 to $700{ }^{\circ} \mathrm{C}$.

In order to further clarify the influences of reduction temperatures on an ammonium perrhenate hydrogen reduction, $\mathrm{X}$-ray photoelectron spectroscopy was used for the rhenium atomic quantitative analysis in different valence states. According to the references [30-32], a rhenium atom has a split energy level (f), where the spin-orbit splitting was $2.4 \mathrm{eV}$, and the spin orbital split intensity ratio of $\operatorname{Re} 4 f_{7 / 2}$ and $\operatorname{Re} 4 f_{5 / 2}$ was $4: 3$. The background was a mixed Shirley background (Shirley + straight line) [33], and the slope of the line was eight. The peak positions and fit paramters for all samples are given in Table 2. The X-ray photoelectron spectroscopy of the reduced products at the different reduction temperatures are shown in Figure A1.

Table 2. The peak positions and fit paramters for $\operatorname{Re} 4 f_{7 / 2}$ and $\operatorname{Re} 4 f_{5 / 2}$.

\begin{tabular}{|c|c|c|c|c|}
\hline Fitting Parameters & $\operatorname{Re}$ & $\operatorname{Re}^{4+}$ & $\operatorname{Re}^{6+}$ & $\operatorname{Re}^{7+}$ \\
\hline B.E $(4 f 7 / 2)$ & 40.31 & 42.7 & 45.2 & 46.1 \\
\hline B.E $(4 \mathrm{f} 5 / 2)$ & 42.71 & 45.1 & 47.6 & 48.5 \\
\hline FWHM & 1.3 & 1.7 & 1.75 & 1.8 \\
\hline
\end{tabular}

The X-ray photoelectron spectroscopy of the reduced products at different reduction temperatures are shown in Figure A1. According to the peak areas of the different valence states of rhenium, the content of each valence state was calculated, as shown in Table 2. The percent of rhenium atom in each valence state was calculated, as shown in Table 3.

Table 3. The percent of rhenium atom in each valence state of the reduction products of ammonium perrhenate $\left(D_{50}\right.$ was $71.17 \mu \mathrm{m}$, specific surface was $26.93 \mathrm{~m}^{2} / \mathrm{kg}$ ) at different temperatures.

\begin{tabular}{|c|c|c|c|c|}
\hline Reduction Temperature $\left({ }^{\circ} \mathrm{C}\right)$ & $\operatorname{Re}(\%)$ & $\operatorname{Re}^{4+}(\%)$ & $\operatorname{Re}^{6+}(\%)$ & $\operatorname{Re}^{7+}(\%)$ \\
\hline 300 & 75.9 & 20.0 & 3.0 & 1.1 \\
\hline 350 & 69.6 & 16.4 & 24.0 & 0.0 \\
\hline 400 & 59.3 & 14.1 & 26.6 & 0.0 \\
\hline 500 & 65.9 & 16.2 & 17.9 & 0.0 \\
\hline 600 & 76.1 & 18.1 & 7.8 & 0.0 \\
\hline 700 & 100 & 0.0 & 0.0 & 0.0 \\
\hline
\end{tabular}


According to the results in Table 3, the percents of rhenium atom in each valence state of the reduced products at different temperatures were plotted, as shown in Figure 6. Combined with Table 2 and Figure 6, it can be concluded that the percent of $\mathrm{Re}^{6+}$ in the reduction products increased in the range of 300 to $400{ }^{\circ} \mathrm{C}$, and within the temperature range of 400 to $600{ }^{\circ} \mathrm{C}$, the percent of Re in the reduction products did not increase significantly, while the content of $\operatorname{Re}^{4+}$ increased significantly. These results showed that the $\mathrm{ReO}_{3}$ content in the reduction products increased in the temperature range of $300-400^{\circ} \mathrm{C}$ and decreased with the increase in the reduction temperature; the Re content decreased in the temperature range of $300-400{ }^{\circ} \mathrm{C}$ and increased with the increase in the reduction temperature. In order to explain this rule, the following conclusions were obtained by combining the XRD and DTA detection results: the disproportionation reaction of $\mathrm{ReO}_{3}$ occurred between 350 and $400{ }^{\circ} \mathrm{C}$, $\mathrm{ReO}_{3}$ decomposed into $\mathrm{ReO}_{2}$ and $\mathrm{Re}_{2} \mathrm{O}_{7}$, and $\mathrm{Re}_{2} \mathrm{O}_{7}$ was converted to $\mathrm{ReO}_{3}$ by a hydrogen reduction. Therefore, in the temperature range of 350 to $400{ }^{\circ} \mathrm{C}$, the effect of disproportionation hindered the normal reduction process, and this is why ammonium perrhenate cannot be reduced to more rhenium at 350 to $400{ }^{\circ} \mathrm{C}$ in the same reduction time. This phenomenon shows that the disproportionation of $\mathrm{ReO}_{3}$ hindered the normal reduction reaction in a certain temperature range, but with the increase in the temperature, the reduction reaction rate gradually increased, and the content of rhenium in the reduction products also increased. At the reduction temperature of $300{ }^{\circ} \mathrm{C}$, the disproportionation of $\mathrm{ReO}_{3}$ did not occur, and only the reduction reaction was carried out. Therefore, the content of Re in the reduction products was higher. As discussed above, in the process of a hydrogen reduction of ammonium perrhenate, the disproportionation of $\mathrm{ReO}_{3}$ decreased the rate of the reduction reaction, and the increase in the temperature can increase the reduction reaction rate and reduce the effect of disproportionation on the reduction process. Increasing the reduction time and lowering the reduction temperature below the temperature at which the disproportionation of $\mathrm{ReO}_{3}$ occurs can also increase the content of Re in the reduction products.

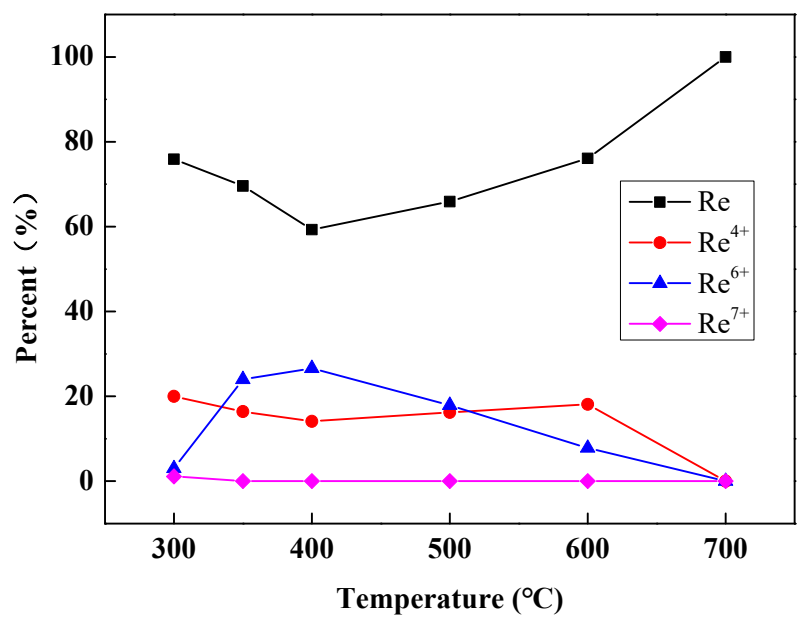

Figure 6. Oxidation state atomic content changes of ammonium perrhenate $\left(D_{50}\right.$ was $71.17 \mu \mathrm{m}$, specific surface was $26.93 \mathrm{~m}^{2} / \mathrm{kg}$ ) hydrogen reduction reaction at different temperatures.

\subsection{Influence of Particle Size on Reduction}

In the solid-state reaction system, the reaction rate is related not only to the temperature but also to the diffusion rate of the reactant [34]. The particle size of the reactant decreases, which is conducive to increasing the diffusion rate [35]. In order to research the effects of particle sizes of ammonium perrhenate on the reduction effect, the recrystallized ammonium perrhenate $\left(D_{50} 81.05 \mu \mathrm{m}\right)$ was used for the reduction experiments under the same operating conditions. The XRD patterns of the reduction products of ammonium perrhenate at different temperatures are shown in Figure 7 . The characteristic peaks of the reduction products were complex at lower temperatures $\left(300-700{ }^{\circ} \mathrm{C}\right)$, and the diffraction peaks of the reduction products indicated $\mathrm{Re}$ and $\mathrm{ReO}_{2}$, and $\mathrm{ReO}_{3}$. The characteristic peaks of $\mathrm{Re}$ did 
not change obviously from 500 to $800{ }^{\circ} \mathrm{C}$. However, in the range of 300 to $400{ }^{\circ} \mathrm{C}$, the characteristic peaks of $\mathrm{ReO}_{3}$ were enhanced. In the range of 500 to $800^{\circ} \mathrm{C}$, the characteristic peaks of $\mathrm{ReO}_{2}$ were enhanced, while that of $\mathrm{ReO}_{3}$ were weakened. When the temperature reached $900{ }^{\circ} \mathrm{C}$, the characteristic peaks of the reduction products were $\mathrm{Re}$ and $\mathrm{ReO}_{2}$, and other crystal peaks were not observed. This result suggested that the contents of $\mathrm{ReO}_{3}$ in the reduction products increased in the range of 300 to $400{ }^{\circ} \mathrm{C}$. However, within the temperature range of 500 to $800^{\circ} \mathrm{C}$, the content of Re in the reduction products did not increase significantly, while the content of $\mathrm{ReO}_{2}$ increased significantly.
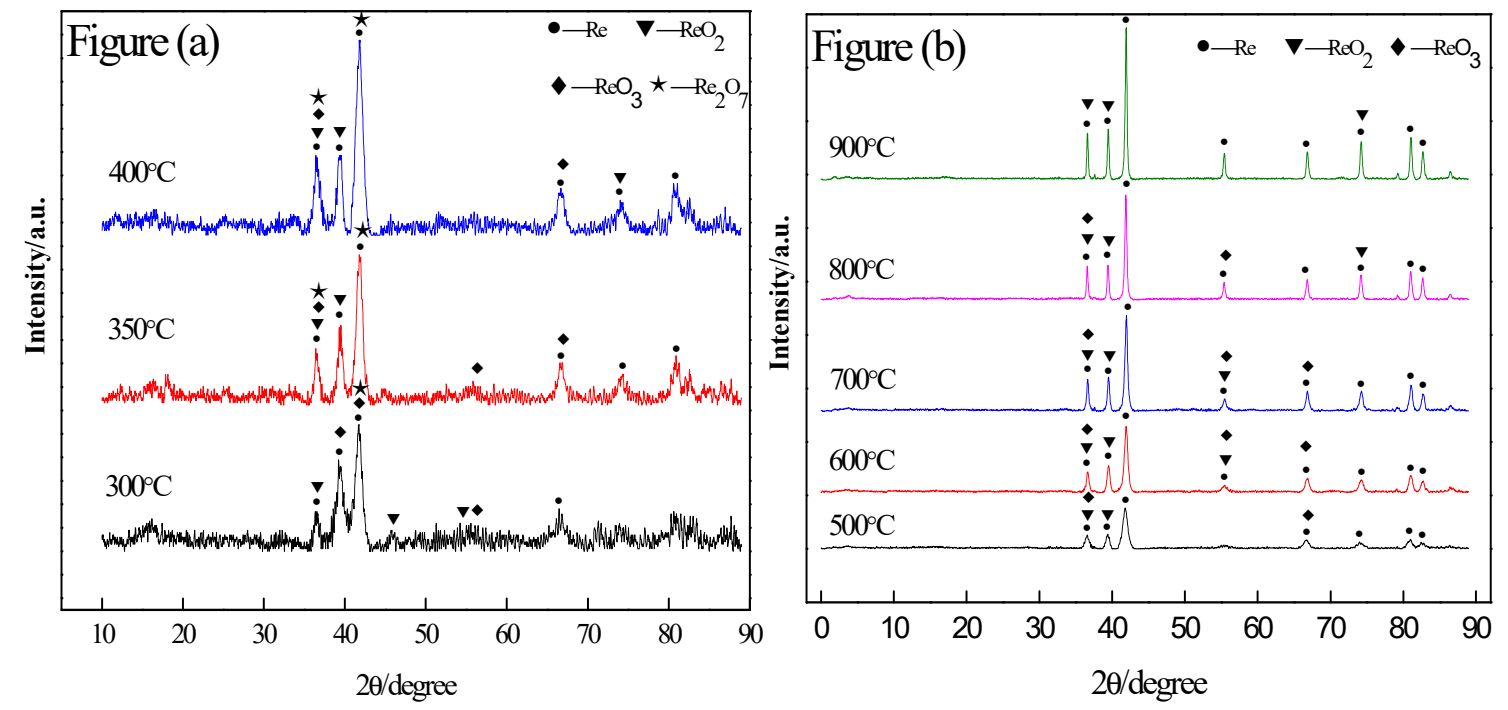

Figure 7. $X R D$ patterns of the reduction products of ammonium perrhenate $\left(D_{50}\right.$ was $81.05 \mu \mathrm{m}$, specific surface was $21.72 \mathrm{~m}^{2} / \mathrm{kg}$ ) at different temperatures. Figure (a) was the XRD diffraction pattern of the reduced product at 300 to $400{ }^{\circ} \mathrm{C}$; Figure (b) was the XRD diffraction pattern of the reduced product at 500 to $900{ }^{\circ} \mathrm{C}$.

In order to further clarify the influence of particle sizes on an ammonium perrhenate hydrogen reduction, X-ray photoelectron spectroscopy was used to quantitatively analyze this feature. The X-ray photoelectron spectroscopy of the reduced products at different reduction temperatures are shown in Figure A2. The percent of rhenium atom in each valence state was calculated, as shown in Table 4 . According to the results in Table 4, the percents of rhenium atom in each valence state of the reduced products at different temperatures were plotted, as shown in Figure 8. Combined with Table 4 and Figure 8, it can be concluded that the content of Re in the reduction products increased with the decrease of $\mathrm{ReO}_{3}$ between 350 and $800{ }^{\circ} \mathrm{C}$. At the reduction temperature of $300{ }^{\circ} \mathrm{C}$, the disproportionation of rhenium trioxide did not occur and the content of rhenium was higher. The composition law of the reduction products was the same as that of previous reduction experiments, which proved the accuracy of the reduction mechanism analysis. When the reduction temperature reached $800{ }^{\circ} \mathrm{C}$, rhenium trioxide still existd. It can be concluded that the disproportionation of $\mathrm{ReO}_{3}$ existed in the range of 350 to $800{ }^{\circ} \mathrm{C}$. Compared with the previous reduction experiment, the temperature range at which the disproportionation reaction occurs had increased. This was because the particle size of ammonium perrhenate increased, the solid reaction diffusion rate decreased, and the contact between the reactant and hydrogen was not ideal. Therefore, under the same operating conditions, reducing the particle size of ammonium perrhenate can increase the hydrogen reduction diffusion rate and reduce the influence of the disproportionation on the reduction process. 
Table 4. The percents of rhenium atom in each valence state of the reduction products of ammonium perrhenate $\left(D_{50}\right.$ was $81.05 \mu \mathrm{m}$, specific surface was $21.72 \mathrm{~m}^{2} / \mathrm{kg}$ ) at different temperatures.

\begin{tabular}{|c|c|c|c|c|}
\hline Reduction Temperature $\left({ }^{\circ} \mathrm{C}\right)$ & $\operatorname{Re}(\%)$ & $\operatorname{Re}^{4+}(\%)$ & $\operatorname{Re}^{6+}(\%)$ & $\operatorname{Re}^{7+}(\%)$ \\
\hline 300 & 65.7 & 20.0 & 10.8 & 3.5 \\
\hline 350 & 58.9 & 21.8 & 19.1 & 0.2 \\
\hline 400 & 36.3 & 10.7 & 45.9 & 7.1 \\
\hline 500 & 68.1 & 15.7 & 16.2 & 0.0 \\
\hline 600 & 72.2 & 18.2 & 9.6 & 0.0 \\
\hline 700 & 72.7 & 22.0 & 5.3 & 0.0 \\
\hline 800 & 79.0 & 17.2 & 3.8 & 0.0 \\
\hline 900 & 80.1 & 19.9 & 0.0 & 0.0 \\
\hline
\end{tabular}

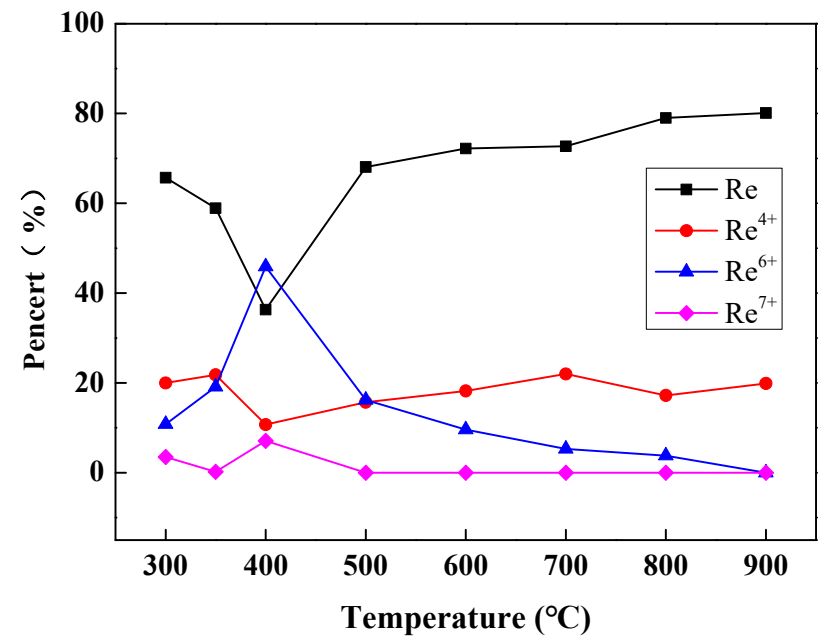

Figure 8. Oxidation state atomic content changes of ammonium perrhenate $\left(\mathrm{D}_{50}\right.$ was $81.05 \mu \mathrm{m}$, specific surface was $21.72 \mathrm{~m}^{2} / \mathrm{kg}$ ) hydrogen reduction reaction at different temperatures.

\subsection{Analysis of the Products of the Rhenium Ingots}

The Re powders were prepared by unrecrystallized ammonium perrhenate and recrystallized ammonium perrhenate with a different $\mathrm{D}_{50}$, and the rhenium ingots were prepared from these rhenium powders. The relevant physical parameters of the products are shown in Table 5 . The particle size distribution of the rhenium powder is shown in Figure 9. It can be seen from Table 5 and Figure 9 that the rhenium powder prepared by ammonium perrhenate with a small particle size is also of relatively small particle size; the particle size distribution uniformity of rhenium powder prepared by recrystallized ammonium perrhenate was improved obviously, and the rhenium ingot prepared has a higher density. The theoretical density of rhenium is $21.04 \mathrm{~g} / \mathrm{cm}^{3}$, and the density of the rhenium ingot prepared by $\mathrm{D}_{50} 71.17 \mu \mathrm{m}$ ammonium perrhenate reached $20.106 \mathrm{~g} / \mathrm{cm}^{3}$. The rhenium ingot prepared under this condition was close to the theoretical density. The SEM images of the surface defects of the rhenium ingots are shown in Figure 10. It can be seen that the rhenium ingot prepared by the small particle size rhenium powder not only has a high density but also has a small surface hole defect. Therefore, reducing the particle size of the rhenium powder is a key factor in preparing a high-density rhenium ingot.

Table 5. The rhenium materials prepared from ammonium perrhenate of different particle sizes.

\begin{tabular}{|c|c|c|c|}
\hline $\begin{array}{l}\mathrm{D}_{50} \text { of Ammonium } \\
\text { Perrhenate }(\mu \mathrm{m})\end{array}$ & $D_{50}$ of Re Powders $(\mu \mathrm{m})$ & $\begin{array}{l}\text { Specific Surface Area of } \\
\operatorname{Re}\left(\mathrm{m}^{2} / \mathrm{kg}\right)\end{array}$ & $\begin{array}{l}\text { Density of Rhenium } \\
\text { Ingots }\left(\mathrm{g} / \mathrm{cm}^{3}\right)\end{array}$ \\
\hline 81.05 & 34.04 & 97.54 & 18.779 \\
\hline 71.17 & 19.74 & 163.70 & 20.106 \\
\hline 123.90 & 52.15 & 72.73 & 17.726 \\
\hline
\end{tabular}



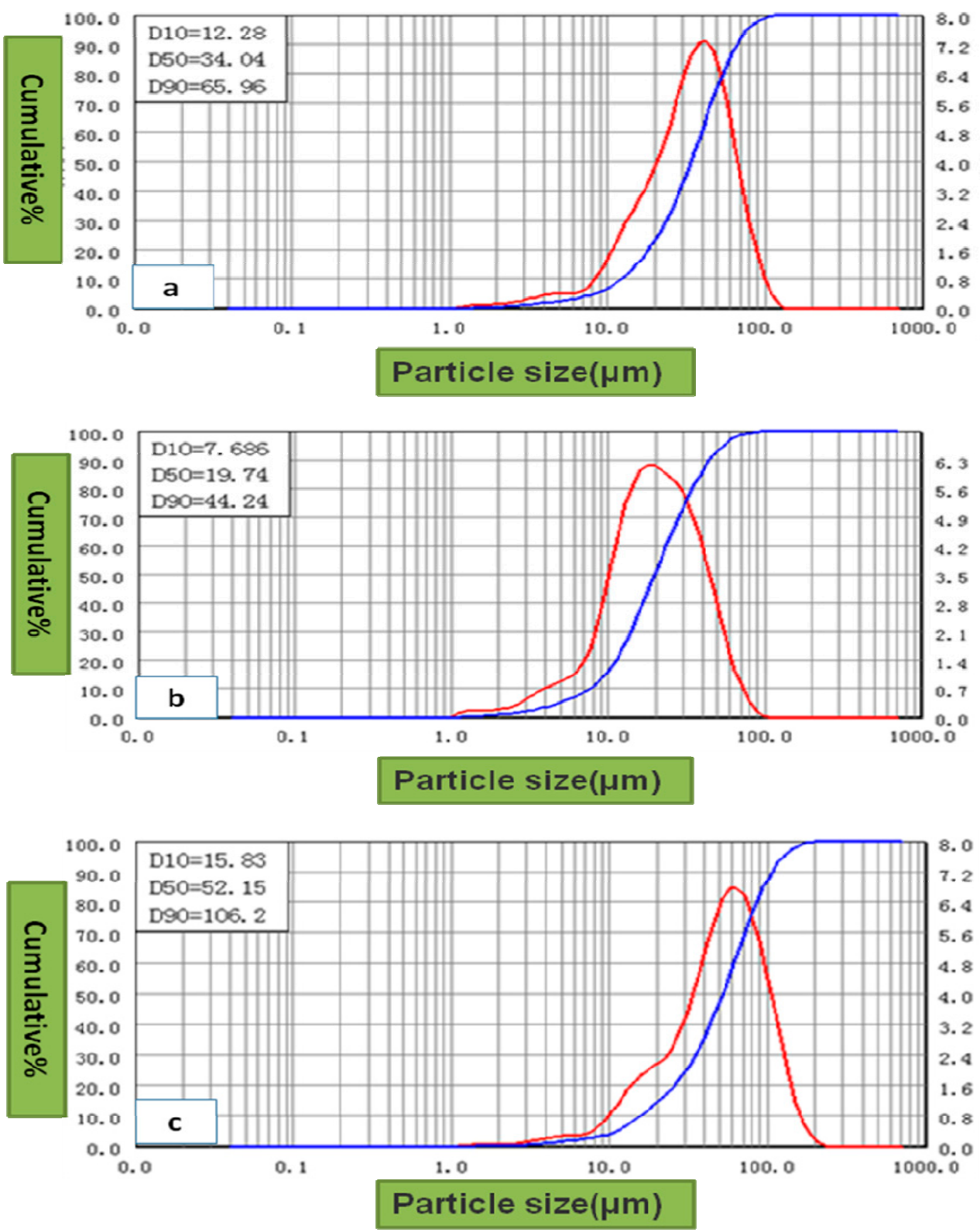

Figure 9. The particle size distribution of rhenium powder prepared by ammonium perrhenate with different particle sizes ((a) prepared by $81.05 \mu \mathrm{m} \mathrm{D}_{50}$ ammonium perrhenate, $(\mathbf{b})$ prepared by $71.17 \mu \mathrm{m}$ $\mathrm{D}_{50}$ ammonium perrhenate, (c) prepared by $123.90 \mu \mathrm{m} \mathrm{D}_{50}$ ammonium perrhenate).
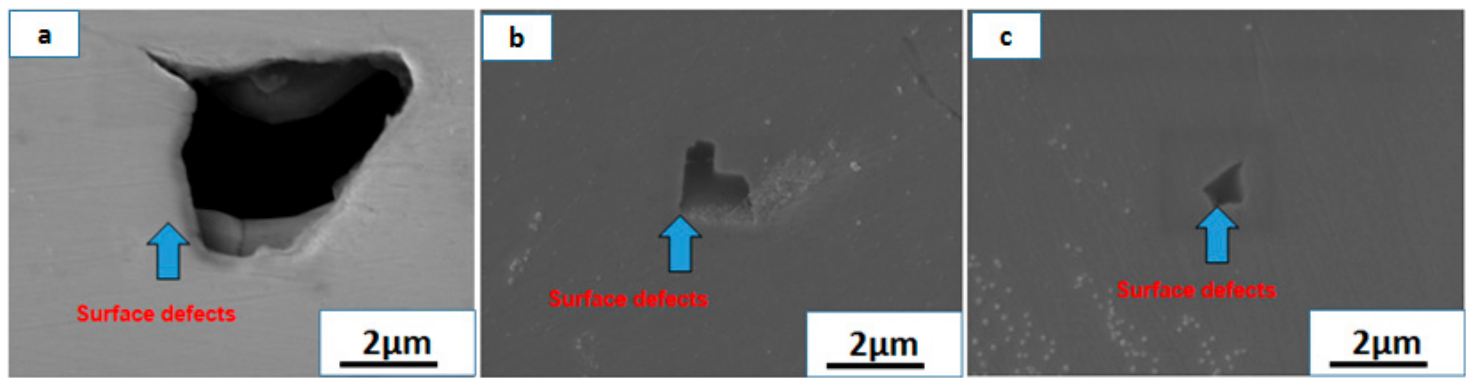

Figure 10. SEM images of the surface defects of the rhenium ingots ((a) prepared by $52.15 \mu \mathrm{m} \mathrm{D}_{50} \operatorname{Re}$ powders, (b) prepared by $34.04 \mu \mathrm{m} \mathrm{D}_{50}$ Re powders, (c) prepared by $19.74 \mu \mathrm{m} \mathrm{D}_{50}$ Re powders). 


\subsection{Proposed Flow Sheet}

Based on the experimental results, the flow sheet for the processing of rhenium ingots by ammonium perrhenate was tentatively suggested, which is shown in Figure 11. The ammonium perrhenate particles were refined by homogeneous recrystallization, and the $\mathrm{D}_{50}$ of the ammonium perrhenate particles was refined from 123.90 to $71.17 \mu \mathrm{m}$. The recrystallized ammonium perrhenate was completely reduced by hydrogen at $700{ }^{\circ} \mathrm{C}$ for $3 \mathrm{~h}$, and the $\mathrm{D}_{50}$ of $19.74 \mu \mathrm{m}$ rhenium powder was obtained. The density of the rhenium ingots pressed by these rhenium powders was $20.106 \mathrm{~g} / \mathrm{cm}^{3}$. The theoretical density of rhenium is $21.04 \mathrm{~g} / \mathrm{cm}^{3}$, and a rhenium ingot that reaches the theoretical density of more than $90 \%$ is a high-quality product. In this study, the rhenium ingot density was $95.56 \%$ of the theoretical density, which reached the high-quality product standard. The optimized production process of rhenium ingot not only realized a low-temperature reduction, but also increased the density of the rhenium ingot, which can provide a theoretical basis and practical experience for industrial production.

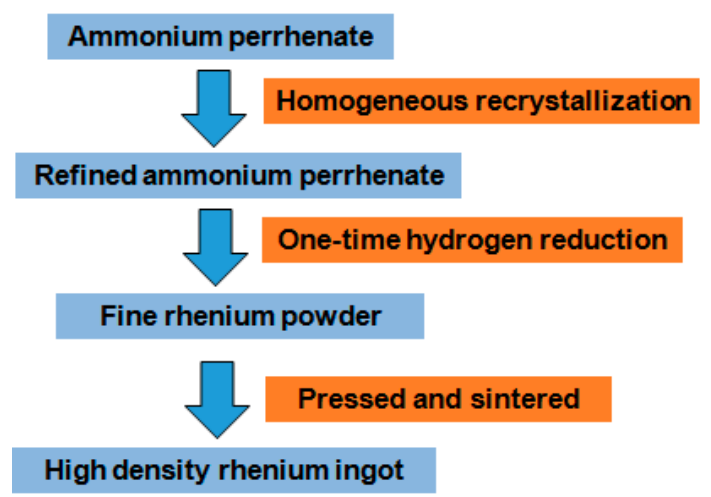

Figure 11. Proposed flow sheet for the preparation of high-density rhenium ingot by homogeneous recrystallization of ammonium perrhenate by a hydrogen reduction.

\section{Conclusions}

In this study, the influences of disproportionation on the hydrogen reduction of ammonium perrhenate were investigated and the following conclusions were drawn:

(1) In the process of a hydrogen reduction of ammonium perrhenate, the disproportionation of $\mathrm{ReO}_{3}$ decreased the rate of the reduction reaction, and the increase in the reduction temperature was conducive to increasing the reduction reaction rate and reducing the influence of disproportionation on the reduction process.

(2) At the same reduction temperature, reducing the particle sizes of ammonium perrhenate was conducive to increasing the hydrogen reduction rate and reducing the influence of the disproportionation on the reduction process.

(3) The rhenium ingot prepared by the small particle size rhenium powder not only has a high density but also has a small surface hole defect. Therefore, reducing the particle size of the rhenium powder is a key factor in preparing high-density rhenium ingot.

(4) It is feasible to increase the density of rhenium ingot by reducing the particle size of the rhenium powder. The particle size of ammonium perrhenate was reduced to a rhenium powder with a $\mathrm{D}_{50}$ of $19.74 \mu \mathrm{m}$ and a specific surface area of $163.70 \mathrm{~m}^{2} / \mathrm{kg}$, which was pressed into a rhenium ingot with a density of $20.106 \mathrm{~g} / \mathrm{cm}^{3}$, close to the theoretical density of rhenium.

Author Contributions: J.T.: Writing—original draft; Data curation; Formal analysis; Investigation; Funding acquisition. Y.S.: Data curation; Formal analysis; Funding acquisition; Resources. C.Z.: Data curation; Software. L.W.: Resources; Writing-review and editing. Y.Z.: Investigation; Supervision; Funding acquisition; Resources. D.F.: Writing-review and editing; Resources. Y.L.: Writing—review and editing; Funding acquisition. All authors have read and agreed to the published version of the manuscript. 
Funding: Liaoning provincial department of science and technology doctoral research initiation fund, grant number 2019-BS-130; Open project fund of key laboratory of ecological metallurgy of polymetallic symbiosis in ministry of education, Northeastern University, grant number NEMM2019003.

Acknowledgments: School of Biomedical \& Chemical Engineering, Liaoning Institute of Science and Technology and the analysis and test center of institute of metals, Chinese academy of sciences undertook the sample test for this study. The authors are grateful for these supports.

Conflicts of Interest: The authors declare no conflict of interest.

\section{Appendix A}
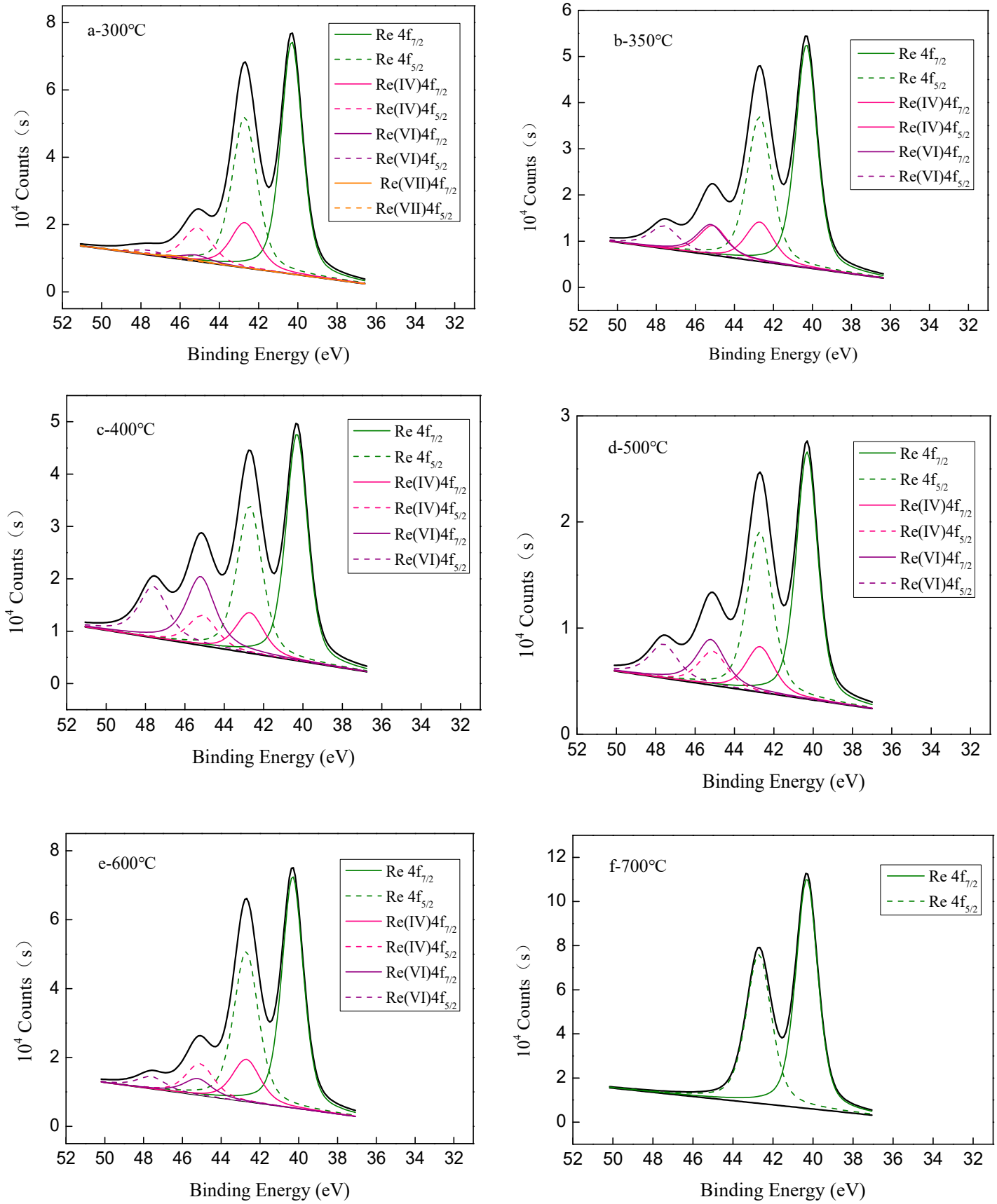

Figure A1. X-ray photoelectron spectroscopy of the reduction products of ammonium perrhenate ( $D_{50}$ was $71.17 \mu \mathrm{m}$, specific surface was $26.93 \mathrm{~m}^{2} / \mathrm{kg}$ ) at different temperatures. 

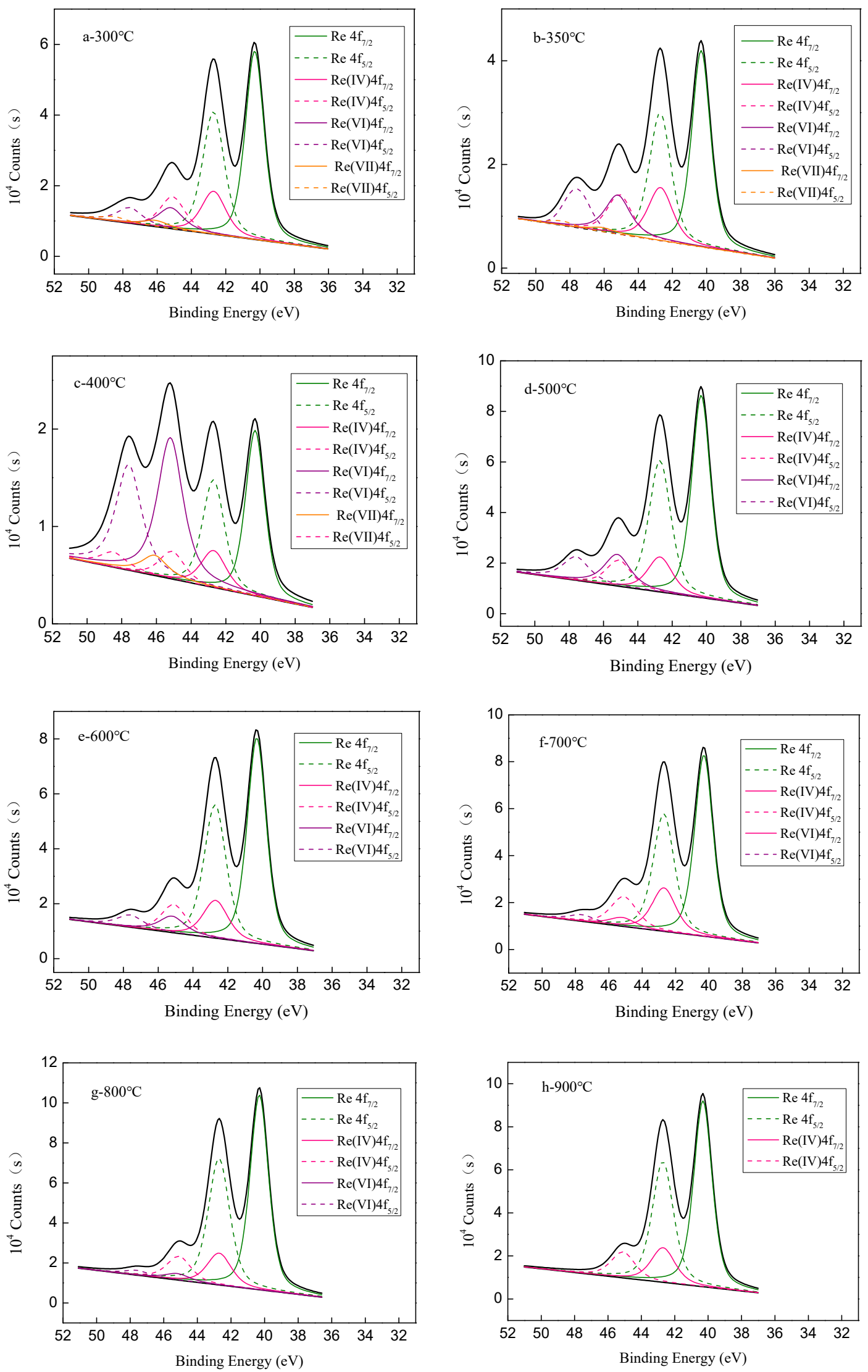

Figure A2. X-ray photoelectron spectroscopy of the reduction products of ammonium perrhenate $\left(\mathrm{D}_{50}\right.$ was $81.05 \mu \mathrm{m}$, specific surface was $21.72 \mathrm{~m}^{2} / \mathrm{kg}$ ) at different temperatures. 


\section{References}

1. Li, L.P.; Liu, Y.; Zhang, W.; Jiang, L.J.; Zhang, W.Z. Recent Development of Rhenium Technology. China Molybdenum Ind. 2016, 40, 1-6.

2. Noar, A.; Eliaz, N.; Gileadi, E.; Taylor, S.R. Properties and applications of rhenium and its alloys. AMMTIAC Q. 2010, 5, 11-14.

3. Li, H.M.; He, X.T.; Zhou, Y.; Guo, J.M.; Han, S.L.; Wang, H.; Li, Y.; Tan, M.L. Resources, Application and Extraction Status of Rhenium. Precious Met. 2014, 35, 77-81.

4. Jurewicz, J.W.; Guo, J.Y. Process for Plasma Synthesis of Rhenium Nano and Micro Powders, and for Coating and New Net Shape Deposits Thereof and Apparatus Therefor. U.S. Patent 2005/0211018A1, 29 September 2005.

5. Leonhardt, T.; Trybus, C.; Hickman, R. Consolidation Methods for Spherical Rhenium and Rhenium Alloys. Powder Metall. 2003, 46, 148-153. [CrossRef]

6. Schrebler, R.; Cury, P.; Orellana, M.; Gómez, H.; Córdova, R.; Dalchiele, E.A. Electrochemical and Nanoelectrogravimetric Studies of the Nucleation and Growth Mechanisms of Rhenium on Polycrystalline Gold Electrode. Electrochim. Acta 2001, 46, 4309-4318. [CrossRef]

7. Liu, Z.H.; Zhang, S.Y.; Liu, Z.Y.; Li, Y.H.; Wang, J. Principle and Research Development of Powder Materials Prepared by Chemical Vapor Deposition. Mater. Sci. Eng. Powder Metall. 2009, 14, 359-364.

8. Stefan, L.; Helumt, A. Hydrogen as a reducing agent: State-of-the-art science and technology. JOM 2007, 59, 20-26.

9. Mannheim, R.L.; Garin, J.L. Microstructural characterization of rhenium powder obtained at various temperatures. Adv. Powder Technol. 2003, 416, 273-282. [CrossRef]

10. Trybus, C.L.; Wang, C.M.; Pandheeradi, M.; Meglio, C.A. Powder metallurgical processing of rhenium. Adv. Mater. Process. 2002, 160, 23-26.

11. Shen, Y.Y.; Yi, X.M.; Liao, B.B. A Preparation Method of High Purity Rhenium Powders. CN Patent NO. 1396027, 12 February 2003.

12. Yang, H.B.; Peng, J.Y.; Cheng, T.Y.; Xiong, N.; Yin, J.C.; Chen, F.X. A Manufacturing Method of Pure Rhenium Flakes with Difficulty in Deformation. CN Patent NO. 101177748A, 14 May 2008.

13. Bartosz, T.; Beata, B.; Kusz, B. A study of a reduction of a micro-and nanometric bismuth oxide in hydrogen atmosphere. Ther. Acta 2018, 669, 99-108.

14. Dang, J.; Wu, Y.J.; Lv, Z.P.; You, Z.X.; Zhang, S.F.; Lv, X.W. A new kinetic model for hydrogen reduction of metal oxides under external gas diffusion controlling condition. Int. J. Refract. Met. Hard Mater. 2018, 77, 90-96. [CrossRef]

15. Liu, Q.P.; Bai, Y.; Yi, S.F.; An, P.F. The Effect of Hydrogen Dew Point on the Properties of Molybdenum Dioxide and Molybdenum Powder. China Tungsten Ind. 2018, 33, 42-46.

16. Zhuo, H.O.; Ye, N.; Zhou, Q.; Liu, W.S.; Tang, J.C. Comparative study of tungsten powders prepared by carbon-hydrogen co-reduction and common hydrogen reduction. Chin. J. Nonferrous Met. 2018, 28, 743-748.

17. Chen, L.J.; Xie, Z.H.; Wang, R.X.; Tian, L.; Nie, H.P. Reduction Carbonization Mechanism Analysis of Tungsten Oxide Powder and Preparation of Ultrafine Tungsten Carbide Powder. Rare Met. Cem. Carbides 2018, 46, 11-20.

18. Song, H.L.; Jiang, P.G.; Liu, W.J.; Wang, Z.B. Research progress on hydrogen reduction kinetics of tungsten oxide. Nonferrous Met. Sci. Eng. 2017, 8, 64-69.

19. Vesel, A.; MoZetic, M.; Marianne, B.P. Sequential oxidation and reduction of tungsten/tungsten oxide. Thin Solid Film 2015, 591, 174-181. [CrossRef]

20. Yu, K.N.; Mao, M.H.; Liang, H.Z.; Xu, J. Preparation of Ultrafine Co Powder from Basic Co(OH $)_{2}$ Slurry by Hydrogen Reduction. Chin. J. Process Eng. 2001, 1, 62-65.

21. Fang, Z.Z.; Wang, H.; Kumar, V. Coarsening, densification, and grain growth during sintering of nano-sized powders-A perspective. Int. J. Refract. Met. Hard Mater. 2017, 62, 110-117. [CrossRef]

22. Wang, D.H.; Sun, G.D.; Zhang, G.H. Preparation of ultrafine Mo powders via carbothermic pre-reduction of molybdenum oxide and deep reduction by hydrogen. Int. J. Refract. Met. Hard Mater. 2018, 75, 70-77. [CrossRef]

23. Kang, H.J.; Jeong, Y.K.; Oh, S.T. Hydrogen reduction behavior and microstructural characteristics of $\mathrm{WO}_{3}$ and $\mathrm{WO}_{3}-\mathrm{NiO}$ powders. Int. J. Refract. Met. Hard Mater. 2019, 80, 69-72. [CrossRef] 
24. Gu, S.Y.; Qin, M.L.; Zhang, H.A.; Ma, J.D.; Qu, X.H. Preparation of Mo nanopowders through hydrogen reduction of a combustion synthesized foam-like $\mathrm{MoO}_{2}$ precursor. Int. J. Refract. Met. Hard Mater. 2018, 76, 90-98. [CrossRef]

25. Colton, R. Some Complex anioks containing rhenium. Aust. J. Chem. 1965, 18, 435-439. [CrossRef]

26. Bai, M.; Liu, Z.H.; Zhou, L.J.; Liu, Z.Y.; Zhang, C.F. Preparation of ultrafine rhenium powders by CVD hydrogen reduction of volatile rhenium oxides. Trans. Nonferrous Met. Soc. China 2013, 23, 538-542. [CrossRef]

27. Zhou, L.J. Research on Preparation of Ultrafine Rhenium Powder by Chemical Vapor Deposition. Master's Thesis, Central South University, Hunan, China, 2010.

28. Tang, J.J.; Sun, Y.; Hou, G.C.; Ding, Y.T.; He, F.; Zhou, Y.Z. Studies on Influencing Factors of Ammonium Rhenate Recovery from Waste Superalloy. Appl. Sci. 2018, 8, 2016. [CrossRef]

29. Tang, J.J.; Feng, L.; Zhang, C.W.; Sun, Y.; Wang, L.; Zhou, Y.Z.; Fang, D.W.; Liu, Y. The Influences of Stirring on the Recrystallization of Ammonium Perrhenate. Appl. Sci. 2020, 10, 656. [CrossRef]

30. Okal, J.; Tylus, W.; Kepi'nski, L. XPS study of oxidation of rhenium metal on $\gamma-\mathrm{Al}_{2} \mathrm{O}_{3}$ support. J. Catal. 2004, 225, 498-509. [CrossRef]

31. Kuznetsov, V.V.; Gamburg, Y.D.; Zhulikov, V.V.; Batalov, R.S.; Filatova, E.A. Re-Ni cathodes obtained by electrodeposition as a promising electrode material for hydrogen evolution reaction in alkaline solutions. Electrochim. Acta 2019, 317, 358-366. [CrossRef]

32. Iqbal, S.; Shozi, M.L.; Morgan, D.J. X-ray induced reduction of rhenium salts and supported oxide catalysts. Surf. Interface Anal. 2017, 49, 223-226. [CrossRef]

33. Zhang, B.; Sun, Y.Z.; Wang, W.H. Line Shapes Used in XPS and Background Subtraction. Phys. Exam. Test. 2011, 1, 18-23.

34. Hillig, W.B.; Adjerid, S.; Flaherty, J.E.; Hudson, J.B. The effect of combined diffusion and kinetic transport barriers on multi-phase solid state reactions with a vapour reactant. J. Mater. Sci. 1996, 31, 5865-5871. [CrossRef]

35. Ler, K.M.K.; Götze, L.C.; Rybacki, E.; Dresen, G.; Abart, R. Enhancement of solid-state reaction rates by non-hydrostatic stress effects on polycrystalline diffusion kinetics. Am. Mineral. 2010, 95, 1399-1407.

(C) 2020 by the authors. Licensee MDPI, Basel, Switzerland. This article is an open access article distributed under the terms and conditions of the Creative Commons Attribution (CC BY) license (http://creativecommons.org/licenses/by/4.0/). 